\title{
Relação entre Densidade de Plantas e Genótipos de Soja ROUNDUP READYTM ${ }^{1}$
}

\author{
Relationship Between Plant Density and Soybean Roundup Ready ${ }^{\mathrm{TM}}$ Genotypes
}

SOUZA, C.A. ${ }^{2}$, GAVA, F. ${ }^{3}$, CASA, R.T. ${ }^{2}$, BOLZAN, J.M. ${ }^{4}$ e KUHNEM JUNIOR. P.R. ${ }^{2}$

\begin{abstract}
RESUMO - A presente pesquisa teve por objetivo estudar a influência de diferentes densidades de plantas e genótipos de soja Roundup Ready ${ }^{\mathrm{TM}}(\mathrm{RR})$ em algumas características morfoagronômicas da soja, semeada em duas safras distintas. O experimento foi conduzido na região dos Campos de Cima da Serra, no Estado do Rio Grande do Sul, nas safras agrícolas 2006/07 e 2007/08, com os cultivares CD 213RR e BRS 255RR, nas densidades de 12, 18, 24, 30 e 36 plantas aptas por $\mathrm{m}^{2}$. O delineamento experimental utilizado foi de blocos ao acaso, com quatro repetições. Para isso, foram avaliados altura de plantas, diâmetro da haste, número de ramificações por planta, número de vagens por planta, número de grãos por planta, número de grãos por vagem, massa de mil grãos e rendimento de grãos por hectare. O manejo das plantas daninhas com glyphosate em duas etapas (pré-semeadura e em V4) evitou eficientemente a matocompetição. $\mathrm{O}$ aumento da densidade de plantas de soja RR promoveu incremento linear da altura das plantas $\left(0,5\right.$ a $0,9 \mathrm{~cm}$ por planta $\left.\mathrm{m}^{-2}\right)$, influenciada pelo genótipo e pelo ano de cultivo. $\mathrm{O}$ diâmetro da haste foi diminuído com o aumento da densidade de plantas de soja RR de forma linear $\left(-0,03\right.$ a $-0,2 \mathrm{~mm}$ por planta $\left.\mathrm{m}^{-2}\right)$. O número de ramos por planta reduziu com o aumento da densidade $(-0,05$ a $-0,19$ ramos por planta). Na segunda safra, o rendimento de grãos e a massa de mil grãos foram menores, afetados por um período de estiagem e também por uma geada no final do ciclo, mais acentuadamente para o CD 213RR. A combinação de maior número de plantas $\mathrm{m}^{-2}$ levou a uma redução do número de vagens por planta e de grãos por vagem, embora de magnitudes distintas entre as cultivares, o que foi discutido pela interação entre os fatores; no entanto, o rendimento de grãos não foi alterado nas diferentes densidades testadas, e sim sofreu influência da safra de cultivo.
\end{abstract}

Palavras-chave: características agronômicas, Glycine max, população de plantas, produtividade.

ABSTRACT -This work studied the influence of different plant densities and Roundup Ready ${ }^{\mathrm{TM}}$ $(R R)$ soybean genotypes, on some morphoagronomic characteristics of soybean sown in two distinct crops. The experiment was carried out in Campos de Cima da Serra in the state of Rio Grande do Sul, Brazil, in the 2006/O7 and 2007/08 growing seasons with CD 213RR and BRS 255RR cultivars, at densities of 12, 18, 24, 30 and 36 suitable plants $m^{-2}$. The experimental layout used was randomized blocks with four repetitions. Plant height, stem diameter, number of ramifications per plant, number of pods per plant, number of grains per plant, number of grains per pod, mass of a thousand grains and yield of grains per hectare were evaluated. Weed plant management with glyphosate in two applications (pre-sowing and V4) efficiently prevented weed competition. Increasing RR soybean plant density led to a linear increase in plant height $\left(0.5\right.$ to $0.9 \mathrm{~cm}$ per plant $\left.\mathrm{m}^{-2}\right)$, influenced by genotype and crop year. Stem diameter reduced linearly with an increase in plant density (-0.03 to

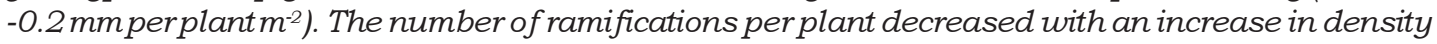
(-0.05 to -0.19 branch per plant). In the second harvest, grain yield and mass of a thousand grains were less affected by drought and frost at the end of the crop cycle, more accentuated in cultivar $C D$ 213RR. A combination of a greater number of plants $m^{-2}$ reduced the number of pods per plant and grains per pod, though by different magnitudes between cultivars, explained by the interaction among various factors. However, grain yield was not affected by the different densities tested, being rather influenced by the growing season.

Keywords: agronomic characteristics, Glycine max, plant population, grain yield.

1 Recebido para publicação em 20.12.2009 e na forma revisada em 12.11.2010.

Parte da dissertação de mestrado do segundo autor.

2 Engo-Agr ${ }^{0}$., Professor, Dep. de Agronomia, Centro de Ciências Agroveterinárias - CAV, Universidade do Estado de Santa CatarinaUDESC, <souza_clovis@cav.udesc.br>,<a2rtc@cav.udesc.br>, <paulo_agro@yahoo.com.br>; ${ }^{3}$ Acadêmico de Mestrado em Produção Vegetal,PPG-Agrárias, UDESC, <fernandogava@hotmail.com>; ${ }^{4}$ Acadêmico de Agronomia, UDESC, <jonatha.bolzan@gmail.com>.

Planta Daninha, Viçosa-MG, v. 28, n. 4, p. 887-896, 2010 


\section{INTRODUÇÃO}

O cultivo da soja (Glycine max) no Brasil é uma das atividades econômicas mais importantes no meio rural, e a venda de grãos para o exterior gera divisas e lucro para o setor produtivo nacional. A região Sul cultiva $38 \%$ da área de total de soja do Brasil. Os Estados do Paraná, Rio Grande do Sul e Santa Catarina, com áreas semeadas na safra de 2008/09 de 4,07, 3,82 e 0,38 milhões de hectares, respectivamente, totalizam 18,4 milhões de toneladas e produtividade média de $2,22 \mathrm{t} \mathrm{ha}^{-1}$ (CONAB, 2008).

Nos últimos anos, a sojicultura nacional experimentou muitas mudanças, tanto no que diz respeito à utilização de novas tecnologias, como quanto ao uso do sistema de semeadura direta e o advento dos cultivares transgênicos Roundup Ready ${ }^{\mathrm{TM}}$, bem como a introdução de cultivares mais produtivos. Entretanto, essas novas variedades de soja apresentam hábito de crescimento e porte diferentes das primeiras linhagens de soja introduzidas no Brasil, o que exigiu mudanças no arranjo de plantas e nos espaçamentos praticados pelos produtores.

Entre os fatores ambientais que exercem efeitos sobre o desenvolvimento da cultura da soja, os mais importantes são a umidade, a temperatura e o fotoperíodo, que variam com as diferentes épocas do ano, apresentando variações mais acentuadas em regiões de maior latitude (Casagrande et al., 2001; Kuss et al., 2008).

Com a adoção do sistema de semeadura direta nas lavouras do Sul do Brasil, houve redução substancial na erosão do solo, melhoria na conservação de nutrientes, aumento da biodiversidade do solo, diminuição das perdas de água e menores oscilações de temperatura (Malavolta, 2006). O sistema de semeadura direta reduz a amplitude térmica do solo, particularmente no Sul do Brasil, durante a primavera - época em que ocorre a semeadura. Esse fato atrasa a elevação de temperatura do solo necessária para atender às exigências da soja, o que acarreta ajuste do período preferencial de semeadura ou alteração na densidade de sementes para corrigir o estande de plantas efetivas (Kuss et al., 2008).

Planta Daninha, Viçosa-MG, v. 28, n. 4, p. 887-896, 2010
Entre as consequências da semeadura em condições ambientais não ideais, com semeadura anterior ou após a época indicada, podem ocorrer redução no rendimento, alterações em algumas características relacionadas com a produção, como altura da planta e de inserção da primeira vagem, número de ramos e número de nós na haste principal (Martins et al., 1999; Peixoto et al., 2001). Segundo Embrapa (2004), essas mudanças fisiológicas e morfológicas são ocasionadas pelo não atendimento das necessidades térmicas e fotoperiódicas, que possivelmente estejam relacionadas com a redução no ciclo da planta. Essa redução se dá principalmente no período reprodutivo (Martins et al., 1999; Motta et al., 2002).

De maneira simultânea à implantação da semeadura direta, ocorreu a introdução de cultivares geneticamente modificados, mudando a base genética dos cultivares e também os produtos utilizados para o manejo das plantas daninhas na cultura. De acordo com Santos et al. (2007), a aplicação de qualquer herbicida sobre as plantas de soja causa algum tipo de estresse, porém este pode ser mais pronunciado, dependendo do genótipo.

A avaliação de cultivares de soja sob diferentes condições de cultivo torna-se fundamental na busca do entendimento do comportamento da cultura numa determinada região geográfica indicada para ela, sendo o ajuste na densidade de plantas uma das práticas de manejo a ser implantada para cada genótipo. Dessa forma, é importante identificar o arranjo de plantas que resulte na competição intraespecífica que permita o melhor aproveitamento dos recursos disponiveis para o crescimento e rendimento de grãos (Rambo et al., 2003).

A população de plantas padrão recomendada pela Embrapa (2008b) para a cultura da soja é de 30 plantas $\mathrm{m}^{-2}$ e em condições de predisposição ao acamamento de 2025 plantas $\mathrm{m}^{-2}$. O uso de populações muito acima da recomendada, além de acarretar aumento nos gastos com sementes, pode levar ao acamamento de plantas e não proporcionar acréscimo na produtividade. Já a adoção de populações abaixo da recomendada favorece $o$ desenvolvimento de plantas daninhas e pode resultar em elevadas perdas no momento da colheita (Vasquez et al., 2008). 
De acordo com Duncan (1986), existem três fases de resposta do rendimento de grãos de soja em função da densidade de plantas: fase I - a densidade de plantas é muito baixa ( 1 a 2 plantas $\mathrm{m}^{-2}$ ), não se verifica competição entre plantas e o rendimento de grãos por planta é máximo; fase II - a planta começa a competir pelos recursos ambientais com a outra (2 a 12 plantas $\mathrm{m}^{-2}$ ); e fase III - caracterizada pela relação positiva entre o aumento na densidade de plantas e o aumento do rendimento de grãos por área (maior que 12 plantas $\mathrm{m}^{-2}$ ), sendo o limite desta fase até interceptação da radiação fotossinteticamente ativa de $95 \%$ para se alcançar o máximo rendimento de grão por área. Esta última fase seria a densidade de plantas a ser alcançada nesta pesquisa.

O presente trabalho objetivou verificar a influência de diferentes densidades de semeadura, genótipos e safras agrícolas nas características morfoagronômicas de planta de soja $R R$, semeada na época indicada para a cultura, sob manejo das plantas daninhas com o herbicida glifosato aplicado em pré-semeadura e no estádio V4.

\section{MATERIAL E MÉTODOS}

Os experimentos foram conduzidos em lavoura de soja na empresa NBN Sementes, no município de Muitos Capões-RS, durante as safras agrícolas de 2006/07 e 2007/08. A lavoura se encontra a 950 metros do nivel do mar, num Latossolo Vermelho distrófico com teor de matéria orgânica próximo de $6 \%, \mathrm{pH}$ 5,6 , níveis de fósforo entre 8 e $12 \mathrm{ppm}$ e de potássio superiores a $200 \mathrm{ppm}$. Os dados climatológicos referentes a precipitação pluvial e temperaturas locais estão apresentados na Tabela 1.

A soja foi semeada nos dias 8 e 12 de dezembro de 2006 e 2007, respectivamente. A cultura foi estabelecida em área sob sistema de semeadura direta em rotação de culturas com milho e sucessão ao trigo. Em ambas as safras utilizaram-se os cultivares BRS 255RR e CD 213RR. O primeiro apresenta como principais características o grupo de maturação precoce, tipo de crescimento determinado, ciclo total de aproximadamente 136 dias (região acima de $800 \mathrm{~m}$ de altitude) e indicação de 22 a 27 plantas $\mathrm{m}^{-2}$ (Embrapa, 2008a). O cultivar CD 213RR pertence ao grupo de maturação precoce, tipo de crescimento determinado, ciclo total de aproximadamente 123 dias e densidade final de 18 a 29 plantas $\mathrm{m}^{-2}$ em regiões de altitude superior a $500 \mathrm{~m}$ (COODETEC, 2009).

A semeadura foi realizada em alta densidade de plantas. Para obtenção das densidades

Tabela 1 - Precipitação pluvial e temperatura média registrada nas safras agrícolas 2006/07 e 2007/08, correspondentes ao período de emergência até desfolha das plantas de soja, em Muitos Capões-RS

\begin{tabular}{|c|c|c|c|c|c|}
\hline \multirow{2}{*}{ Mês } & \multirow{2}{*}{ Decêndio } & \multicolumn{2}{|c|}{ Precipitação pluvial (mm) } & \multicolumn{2}{|c|}{ Temperatura média $\left({ }^{\circ} \mathrm{C}\right)^{\underline{2} /}$} \\
\hline & & $2006 / 07$ & $2007 / 08$ & $2006 / 07$ & $2007 / 08$ \\
\hline \multirow{2}{*}{ Dezembro } & 2 & 110 & 40 & 19,2 & 19,6 \\
\hline & 3 & 35 & 126 & 20,5 & 21,1 \\
\hline \multirow{3}{*}{ Janeiro } & 1 & 68 & 24 & 20,5 & 20,7 \\
\hline & 2 & 61 & 60 & 20,6 & 21,1 \\
\hline & 3 & 79 & 50 & 20,8 & 21,6 \\
\hline \multirow{3}{*}{ Fevereiro } & 1 & 72 & 37 & 19,9 & 20,7 \\
\hline & 2 & 93 & 9 & 19,8 & 20,3 \\
\hline & 3 & 137 & 35 & 19,8 & 19,6 \\
\hline \multirow{3}{*}{ Março } & 1 & 49 & 30 & 19,4 & 19,7 \\
\hline & 2 & 83 & 20 & 18,3 & 18,8 \\
\hline & 3 & 15 & 10 & 17,3 & 16,8 \\
\hline \multirow{3}{*}{ Abril } & 1 & 48 & 27 & 16,4 & 16,2 \\
\hline & 2 & 28 & 57 & 16,3 & 15,1 \\
\hline & $3^{\frac{1 /}{\prime}}$ & 46 & 75 & 16,0 & 13,0 \\
\hline \multicolumn{2}{|c|}{ Total } & 924 & 600 & & \\
\hline
\end{tabular}

${ }^{1 /}$ Final de abril: plantas de soja aproximadamente em estádio $\mathrm{R}_{8}$, aptas para desfolha. ${ }^{2 /}$ Fonte: INMET (2009). 
desejadas, realizou-se o desbaste no estádio V1 (folha completamente desenvolvida do nó cotiledonar). A descrição dos estádios fenológicos de desenvolvimento da planta seguiu a escala de Fehr \& Caviness (1977), mantendose $12,18,24,30$ e 36 plantas $\mathrm{m}^{-2}$ com espaçamento entre linhas de $0,45 \mathrm{~m}$. A adubação da soja consistiu na aplicação de fósforo na linha de semeadura $\left(200 \mathrm{~kg} \mathrm{ha}^{-1}\right.$ da fórmula 00-42-00) e de cloreto de potássio em cobertura (100 $\mathrm{kg} \mathrm{ha}^{-1}$ da fórmula 00-00-60), ambos disponibilizados na cultura do trigo, em quantidades baseadas nas recomendações de adubação da soja descritas pela Comissão de Química e Fertilidade do Solo - RS/SC (CQFSRS/SC, 2004). O controle de plantas daninhas foi efetuado pela aplicação de glifosato (960 g i.a. ha $\left.{ }^{-1}\right)$ em duas etapas: uma 15 dias antes da semeadura e a outra quando as plantas se encontravam no estádio $\mathrm{V} 4$, aos 32 dias após a emergência, em ambas as safras.

As unidades experimentais constaram de parcelas com $5 \mathrm{~m}$ de largura e $10 \mathrm{~m}$ de comprimento, arranjadas em delineamento experimental de blocos ao acaso, com quatro repetições.

Durante o desenvolvimento das plantas, os tratos culturais seguiram as indicações técnicas para a cultura da soja (Embrapa, 2008a). No controle químico de doenças foram realizadas duas aplicações de fungicida (piraclostrobina 66,5 g i.a. ha ${ }^{-1}+$ epoxiconazole $25 \mathrm{~g}$ i.a. ha ${ }^{-1}$ ), visando ao controle de oídio, ferrugem-asiática e manchas foliares, nos estádios R5.1 (10\% da granação) e R5.5 (75\% da granação).

Em cada parcela, por ocasião da colheita, foram amostradas 20 plantas aleatórias da área útil, para as seguintes determinações: altura de plantas, diâmetro da haste, número de ramificações por planta, número de vagens por planta, número de grãos por planta, número de grãos por vagem e massa de mil grãos. Para avaliação do rendimento de grãos, realizou-se a colheita manual das plantas em cinco metros lineares de quatro linhas do centro da parcela, perfazendo $9 \mathrm{~m}^{2}$ de área útil. As plantas foram trilhadas em trilhadora estacionária acionada por motor elétrico. Foi feita limpeza dos grãos, com posterior pesagem. O rendimento de grãos foi calculado em $\mathrm{kg} \mathrm{ha}^{-1}$, com base na área útil de cada parcela e com a umidade dos grãos corrigida para $13 \%$.

Os dados obtidos foram submetidos à análise de variância pelo teste $\mathrm{F}$ a $5 \%$ de probabilidade de erro. Os graus de liberdade da interação dos resultados foram desdobrados por meio de efeito simples. Os resultados da relação entre densidade de plantas e genótipo, por caráter avaliado, foram submetidos à análise de regressão. Quando significativas, as médias foram comparadas pelo teste de Tukey a 5\%. A relação entre variáveis foi efetuada por correlação de Pearson. Ressalta-se que na primeira safra (2006/07), para o cultivar BRS 255RR, as parcelas referentes as densidades de 30 e 36 plantas $\mathrm{m}^{-2}$ foram perdidas, e a respectiva análise foi efetuada considerando essas perdas.

\section{RESULTADOS E DISCUSSÃO}

O manejo das plantas daninhas com glifosato em duas etapas consecutivas - em pré-semeadura; e uma segunda aplicação, quando as plantas de soja estavam em estádio V4 - foi eficiente em evitar a matocompetição nas duas safras de cultivo de soja. Além disso, não foi reportado o desenvolvimento de plantas daninhas resistentes ao glifosato, como trapoeraba (Commelina benghalensis), buva (Connyza bonnariensis) e leiteiro (Euphorbia heterophylla).

Foi encontrada interação entre safra $x$ cultivar para os fatores altura de planta (EP), diâmetro da haste $(\mathrm{DH})$, massa de mil grãos (MMG) e rendimento de grãos (RG) e de cultivar $\mathrm{x}$ densidade apenas para número de ramificações por planta (NRP) (Tabela 2). Não foi detectada interação entre safra $\mathrm{x}$ cultivar $\mathrm{x}$ densidade de planta, nem entre ano $\mathrm{x}$ densidade.

A ocorrência de interação entre safra $x$ cultivar indica que a altura de planta aumentou linearmente de 0,5 a $0,9 \mathrm{~cm}$ para cada planta a mais por $\mathrm{m}^{-2}$. Na primeira safra, o BRS 255RR apresentou maior altura que CD 213RR, sendo $\left.81 \mathrm{~cm} \mathrm{(12} \mathrm{plantas} \mathrm{m}^{-2}\right)$ com aumento de $0,9 \mathrm{~cm}$ por planta $\mathrm{m}^{-2}$ para a BRS 255RR; e CD 213RR com $73 \mathrm{~cm}$ (12 plantas $\left.\mathrm{m}^{-2}\right)$ e incremento de $0,56 \mathrm{~cm}$ por planta $\mathrm{m}^{-2}$. $\mathrm{Na}$ segunda safra, o cultivar BRS 255RR apresentou menor altura que o CD $213 R R$, 
Tabela 2 - Resultado da análise de variância (quadrado médio) para as características morfoagronômicas de soja de dois cultivares, em dois anos agrícolas, na região de Vacaria-RS

\begin{tabular}{|l|c|c|c|c|c|c|c|c|c|}
\hline \multicolumn{1}{|c|}{ FV } & GL & $\mathrm{EP}^{\underline{1}}$ & DH & NR & VP & GP & GV & MMG & RG \\
\hline Ano (A) & 1 & $677,00^{*}$ & $2,16^{*}$ & 0,014 & $14,540^{*}$ & $22,571^{*}$ & 0,012 & $49.693,7^{*}$ & $55.532 .762^{*}$ \\
\hline Cultivar (C) & 1 & $128,00^{*}$ & 0,36 & $3,207^{*}$ & $21,930^{*}$ & 5,413 & $0,361^{*}$ & $24.842,6^{*}$ & $2.571 .033^{*}$ \\
\hline A x C & 1 & $1.434,74^{*}$ & $11,94^{*}$ & 0,001 & 0,147 & 0,280 & 0,014 & $4.334,8^{*}$ & $4.423 .287^{*}$ \\
\hline Densidade (D) & 4 & $571,52^{*}$ & $6,60^{*}$ & $0,260^{*}$ & $11,590^{*}$ & $26,087^{*}$ & 0,005 & 138,6 & 152.852 \\
\hline A x D & 4 & 10,73 & 1,35 & 0,001 & 0,465 & 1,276 & 0,003 & 125,7 & 135.886 \\
\hline C x D & 4 & 7,71 & 0,68 & $0,097^{*}$ & 0,967 & 1,274 & 0,014 & $345,6^{*}$ & 190.422 \\
\hline A x C x D & 2 & 13,99 & 0,78 & 0,005 & 0,675 & 1,357 & $<0,001$ & 18,2 & 38.721 \\
\hline Bloco & 3 & 13,87 & 0,26 & 0,000 & 1,108 & 0,487 & 0,011 & 76,4 & 125.647 \\
\hline Erro & 46 & 15,27 & 0,54 & 0,019 & 0,479 & 1,929 & 0,004 & 94,2 & 97.181 \\
\hline Total & 66 & - & - & - & - & - & - & - & - \\
\hline CV (\%) & - & 4,07 & 8,49 & 4,14 & 13,72 & 13,50 & 3,64 & - & 7,31 \\
\hline
\end{tabular}

1/ EP: altura de planta; DH: diâmetro da haste; NR: número de ramificações; VP: número de vagens por planta; GP: número de grãos por planta; GV: número de grãos por vagem; MMG: massa de mil grãos; e RG: rendimento de grãos. * significativo pelo teste $\mathrm{F}$ a $5 \%$ de probabilidade de erro.

sendo $78 \mathrm{~cm}\left(12\right.$ planta $\left.\mathrm{m}^{-2}\right)$ e aumentando $0,77 \mathrm{~cm}$ por planta $\mathrm{m}^{-2}$; e o CD $213 \mathrm{RR}$ com $\left.85 \mathrm{~cm} \mathrm{(12} \mathrm{planta} \mathrm{m}^{-2}\right)$ e com incremento de $0,75 \mathrm{~cm}$ por planta $\mathrm{m}^{-2}$ (Figura 1A, B). Esses resultados demonstram que o aumento da densidade de plantas por área promove aumento da altura de plantas de soja Roundup Ready $^{\mathrm{TM}}$ quando semeadas em dezembro, mesmo sendo época recomendada na região de Muitos Capões-RS, com 950 m de altitude, demonstrando que as características intrinsecas ao genótipo são afetadas pela alteração da densidade de plantas. Marchiori et al. (1999) constataram que, quanto maior a densidade de plantas de soja na linha, maior a altura final das plantas, menor o diâmetro da haste principal e menor o número de ramificações por planta.

O diâmetro da haste foi de $9,0 \mathrm{~mm}$ na safra $2006 / 07$ e de $8,4 \mathrm{~mm}$ na safra 2007/08. Como houve interação ano $\mathrm{x}$ cultivar, associado ao efeito isolado de densidade, o diâmetro da haste diminuiu linearmente de $0,2 \mathrm{~mm}$ para $0,05 \mathrm{~mm}$ por planta $\mathrm{m}^{-2}$, nas safras $2006 / 07$ e 2007/08, respectivamente, no cultivar BRS 255RR. No cultivar CD 213RR, a redução foi de $0,09 \mathrm{~mm}$ para $0,03 \mathrm{~mm}$ por planta $\mathrm{m}^{-2}$, nas safras 2006/07 e 2007/08, respectivamente (Tabela 2 e Figura 1). Entretanto, na primeira safra houve efeito mais acentuado da densidade de plantas sobre a redução do diâmetro da haste. Diminuição do diâmetro da haste em função do aumento da densidade de plantas também foi observada por outros pesquisadores (Marchiori et al., 1999).

O número de ramificações por planta apresentou interação cultivar x densidade, com resposta linear negativa ao aumento da densidade. O cultivar BRS 255RR apresentou em média 5,5 ramificações por planta, com redução de 0,26 ramificação por planta para cada planta a mais $\mathrm{m}^{-2}$. O cultivar CD 213RR apresentou 9,7 ramificações por planta, e estas foram reduzidas em 0,05 ramificação por planta para cada planta a mais por $\mathrm{m}^{2}$, independentemente da safra de cultivo (Tabela 2 e Figura 1). Entretanto, observou-se efeito compensatório positivo para esses cultivares Roundup Ready ${ }^{\mathrm{TM}}$, pois a redução do número de ramificações por planta foi compensada pelo maior número de plantas por área. Esse efeito compensatório também foi descrito por Peixoto et al. (2000). Segundo Oz (2008), o número de ramificações por planta, VP, RG por planta e a MMG diminuem com o aumento da densidade de plantas, mas o rendimento de grãos não foi afetado em densidade entre 14 e 28 plantas $\mathrm{m}^{-2}$. A diminuição do número de ramificações por planta pode estar relacionada com a concorrência intraespecífica, a qual é aumentada com o incremento do número de plantas por área, alterando diretamente o número de ramos por planta. Resultados semelhantes foram observados por Martins et al. (1999), porém não se avaliou a quantidade de ramos por área, o que leva a inferir que sob influência 
de maior densidade de plantas tenha ocorrido diminuição do número de ramificações por planta e, consequentemente, por área. Embora neste estudo o comportamento tenha sido diferenciado entre cultivares Roundup Ready ${ }^{\mathrm{TM}}$, ambos os cultivares responderam negativamente ao número de ramificações com o aumento da densidade de plantas.
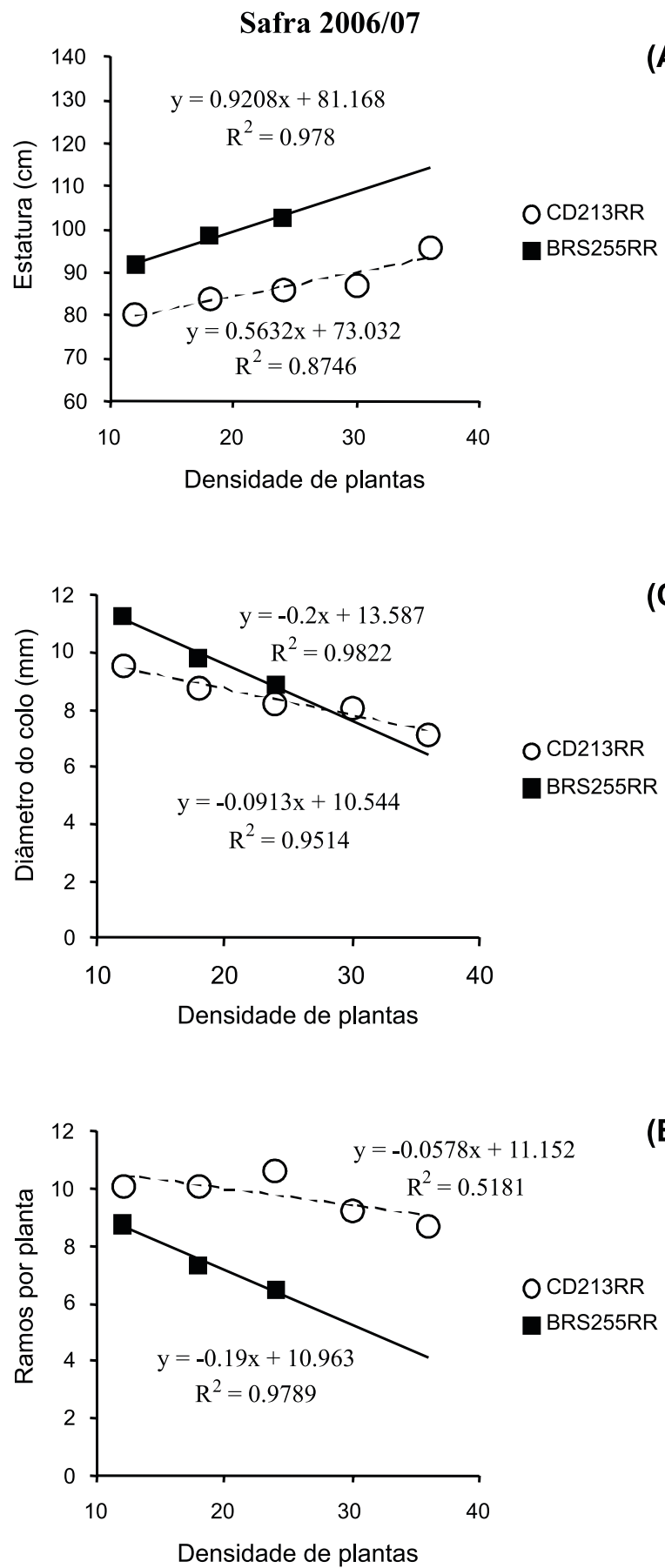

(A)

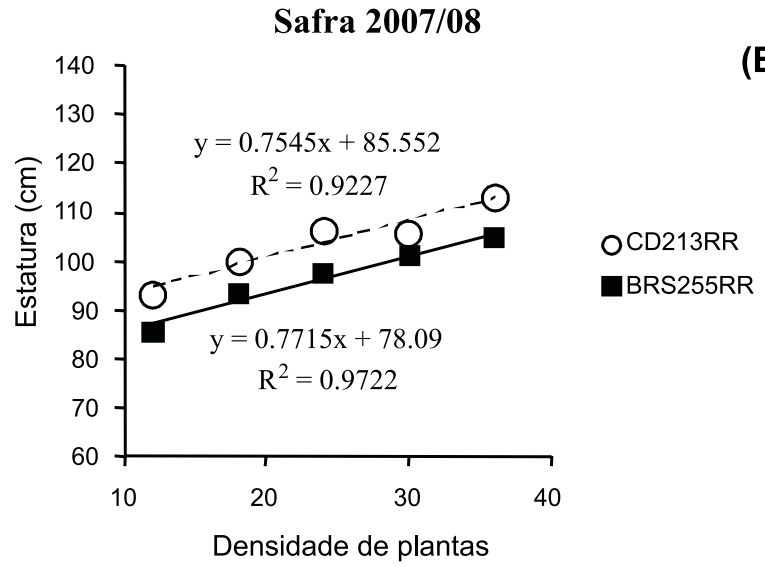

(B)

(C)

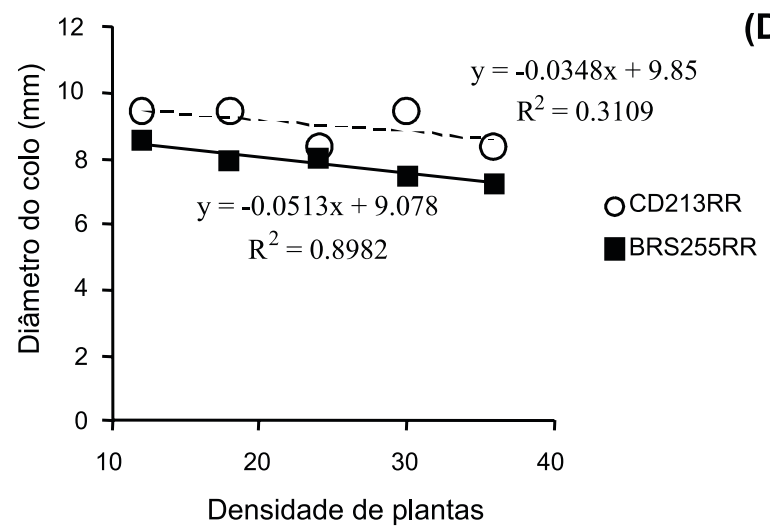

(D)

(E)

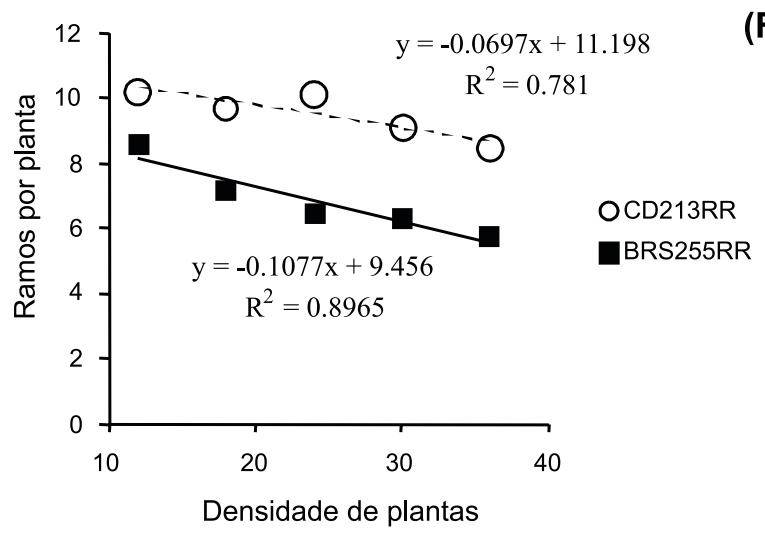

(F)

Figura 1 - Altura de planta (A e B), diâmetro da haste (C e D) e número de ramificações por planta (E e F) de dois cultivares de soja em cinco densidades de plantas e em duas safras agrícolas (2006/07, coluna da esquerda, e 2007/08, coluna da direita). Muitos Capões-RS 
O número de vagens por planta foi de $64 \mathrm{VP}$ na safra 2006/07 e 45 VP na safra 2007/08. O cultivar CD 213RR apresentou maior VP nas duas safras, cujo comportamento de VP diminuiu linearmente de 1,9 para $1,8 \mathrm{VP}$ por planta $\mathrm{m}^{-2}$ a mais, nas safras 2006/07 e 2007/ 08, respectivamente. No cultivar BRS 255RR,

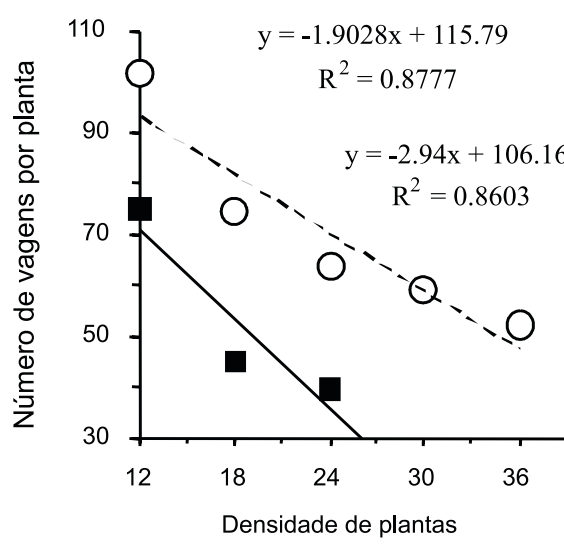

(A)
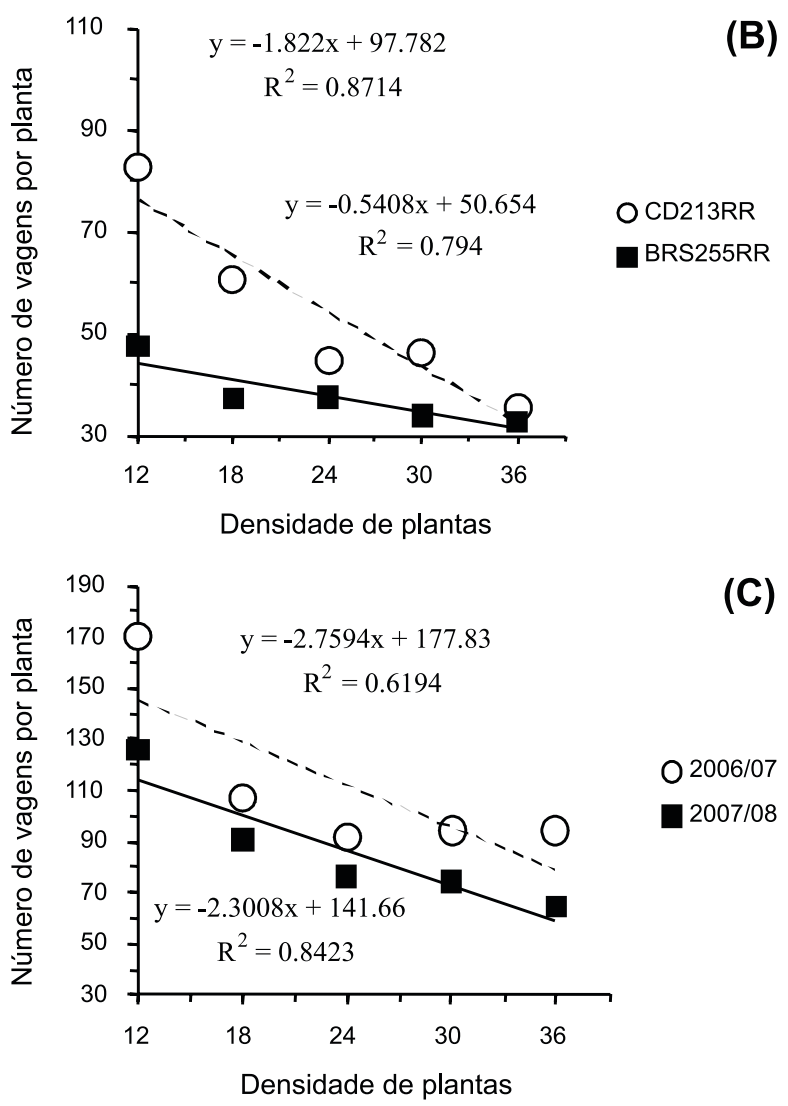

Figura 2 - Número de vagens por planta nas safras 2006/07 (A) e 2007/08 (B) e número grãos por planta (C) em ambas as safras agrícolas de dois cultivares de soja em cinco densidades de planta. Muitos Capões-RS a redução foi de 2,94 e 0,55 VP por planta $\mathrm{m}^{-2}$ a mais, nas safras 2006/07 e 2007/08, respectivamente (Tabela 2 e Figura 2). Esse comportamento de VP também está documentado na literatura $(\mathrm{Oz}, 2008)$.

O número médio de grãos por planta foi de 116 GP na safra 2006/07 e 86 GP na safra $2007 / 08$. O aumento da densidade de plantas afetou negativamente o GP, com efeito linear de 2,8 e 2,3 GP por planta $\mathrm{m}^{-2}$ a mais, na safra 2006/07 e 2007/08, respectivamente, independentemente do cultivar (Tabela 2 e Figura 2). Segundo Oz (2008), o rendimento de grãos por planta diminui com o aumento da densidade. Em outros trabalhos com densidade de plantas variando de 7 a 35 (Heiffig et al., 2006) e de 31,1 a 40 plantas $\mathrm{m}^{-2}$ (Linzmeyer Junior et al., 2008), respectivamente, o RG não foi influenciado pela alteração da densidade, bem como o VP, GV e MMG (Linzmeyer Junior et al., 2008).

O número médio de grãos por vagem foi de 1,7 GV para o cultivar BRS 255RR e 2,1 GV no cultivar CD 213RR, independentemente da safra e da densidade de plantas. O GV é um caráter genotípico e sofre pouca influência do ambiente. Resultados semelhantes foram obtidos em outras pesquisas (Kuss et al., 2008; Linzmeyer Junior et al., 2008; Karasu et al., 2009).

A massa de mil grãos (MMG) apresentou efeito de safra, de cultivar e interação safra $x$ cultivar. Dessa forma, no cultivar CD 213RR, a MMG foi de $155,7 \mathrm{~g}$ e $78,6 \mathrm{~g}$ para as safras 2006/07 e 2007/08, respectivamente - uma redução de 50\% na MMG. O cultivar BRS 255RR apresentou MMG de 171,2 g e 138,3 g para as safras 2006/07 e 2007/08, respectivamente uma redução de apenas 19,2\% na MMG (Tabela 3).

Nesta pesquisa não houve efeito de densidade de plantas sobre o rendimento de grãos nem sobre a MMG, mas observou-se redução no número de vagens por planta e do número de grãos por planta. Sugere-se que a relação fonte-dreno foi alterada entre plantas quando se modificou a densidade, mas foi mantida por unidade de área. Essa constatação pode explicar, pelo menos em parte, o efeito compensatório por planta. Segundo Fageria et al. (2006), em soja, o período do ciclo que mais altera o 
Tabela 3 - Massa de mil grãos (MMG) e rendimento de grãos (RG) dos cultivares CD 213RR e BRS 255RR nas safras 2006/07 e 2007/08. Lages-SC, 2009

\begin{tabular}{|l|c|c|}
\hline \multirow{2}{*}{ Cultivar } & \multicolumn{2}{|c|}{ Massa de mil grãos (g) } \\
\cline { 2 - 3 } & Safra 2006/07 & Safra 2007/08 \\
\hline CD 213RR & $155,7 \mathrm{aA}$ & $78,6 \mathrm{aB}$ \\
\hline BRS 255RR & $171,2 \mathrm{bA}$ & $138,3 \mathrm{bB}$ \\
\hline & \multicolumn{2}{|c|}{ Rendimento de grãos $\left(\mathrm{kg} \mathrm{ha}^{-1}\right)$} \\
\hline CD 213RR & $3516 \mathrm{aA}$ & $1148 \mathrm{aB}$ \\
\hline BRS 255RR & $3185 \mathrm{aA}$ & $2088 \mathrm{bB}$ \\
\hline
\end{tabular}

Médias seguidas pela mesma letra, minúscula na vertical e maiúscula na horizontal, não diferem significativamente entre si pelo teste de Tukey $(5 \%)$

rendimento de grãos, por restrição da fonte, é entre os estádios $R_{1}$ e $R_{5}$, por afetar diretamente o número de vagens, e a partir de $R_{6}$ a força dos drenos é maior e não dependente de formação de novas fontes, e sim de sua manutenção. Nesse aspecto, a massa de cada grão é diretamente dependente da manutenção da fonte até o final do estádio $R_{6}$. Outra observação de Fageria et al. (2006) é que os atuais cultivares de soja apresentam maior indice de colheita - resultado de redução do tamanho da fonte comparada ao tamanho do dreno - e que, para sustentar o aumento do rendimento de grãos, ocorreu necessariamente aumento da eficiência da fonte.

Neste trabalho não foi detectada diferença significativa no rendimento de grãos de soja nos cultivares CD 213RR e BRS 255RR em função do aumento da densidade de plantas (Tabelas 2 e 3). A baixa densidade de plantas não afetou o rendimento de grãos, devido à boa fertilidade do solo e demais recursos ambientais disponiveis. Contudo, houve diferença significativa no rendimento de grãos entre cultivares, entre safra e na interação cultivar x safra (Tabelas 2 e 3). Na safra 2007 não houve diferença de rendimento de grãos, comparando-se apenas cultivares (Tabela 3 ). No entanto, na safra $2007 / 08$, o cultivar BRS 255RR obteve maior RG (Tabelas 2 e 3). Os menores RG e MMG no cultivar CD 213RR são parcialmente explicados pela ocorrência de estiagem de meados de fevereiro a final de março de 2008 e de geada no final de ciclo na safra 2007/08 (Tabela 1), a qual afetou a formação e enchimento de grãos mais acentuadamente para o cultivar CD 213RR (Tabela 2 e 3), por ser de ciclo mais curto (123 contra 135 dias) e, provavelmente, com menor capacidade de recuperação após estresse hídrico ocorrido durante os estádios $R_{4}$ a $R_{7}$.

A escolha da densidade de plantas interfere no manejo integrado da soja, uma vez que densidades indicadas pela pesquisa e assistência técnica buscam conferir estabilidade produtiva para os cultivares de soja, sob condições similares de manejo e ambiente. Por exemplo, Arce et al. (2009) avaliaram o rendimento de grãos de três cultivares sob densidade de plantas de 24 a 42 plantas $\mathrm{m}^{-2}$ e concluíram que as densidades mais altas proporcionam maior rendimento de grãos, mas o trabalho foi efetuado sob competição com plantas daninhas, distinto, portanto, deste experimento. No entanto, Peixoto et al. (2000) avaliaram épocas de semeadura, normal, tardia e safrinha, e densidade de plantas de 24, 40 e 60 plantas $\mathrm{m}^{-2}$ e concluíram que o fator densidade afeta pouco o rendimento de grãos, quando comparado ao fator época de semeadura, cuja influência é maior.

Os resultados desta pesquisa indicam haver relação entre algumas características morfoagronômicas; a magnitude dessa relação foi explorada via análise de correlação simples, a qual se mostrou negativa entre densidade e número de ramificações por planta $(r=-0,35)$ e densidade e número de vagens por planta $(r=-0,62)$, bem como entre densidade e altura de plantas. Essas relações sugerem haver capacidade compensatória da densidade de plantas sobre cada caráter avaliado. No entanto, a correlação simples positiva foi observada entre rendimento de grãos e os componentes da produção (VP, $r=0,41$; GP, $r=0,44$ e MMG, $r=0,90)$ (Tabela 4). Isso ressalta a importância do manejo da densidade de plantas adequada à disponibilidade de recursos ambientais para maximizar o rendimento de grãos. Para essa região, a densidade de semeadura de 12 a 36 plantas $\mathrm{m}^{-2}$ não resultou em diferenças de RG, mas alterou as características morfoagronômicas da planta (EP, DH, NH, NV e GP). Esses resultados sugerem que existe uma fase IV, em que o aumento da densidade de plantas não altera o rendimento de grãos, diferentemente da fase III (aumento da densidade de plantas aumenta o rendimento de grãos), descrita por Duncan (1986). A alteração da 
Tabela 4 - Estimativa dos coeficientes de correlação simples (r) entre cinco densidades de plantas e alguns caracteres morfoagronômicos de dois cultivares de soja em duas safras agrícolas

\begin{tabular}{|l|c|}
\hline \multicolumn{1}{|c|}{ Característica morfoagronômica } & Densidade de plantas (r) \\
\hline Número de ramificações por planta & $-0,35^{*}$ \\
\hline Número de vagens por planta & $-0,44^{*}$ \\
\hline Altura de planta & $-0,62^{*}$ \\
\hline & Rendimento de grãos (r) \\
\hline Número de plantas m ${ }^{-2}$ & $0,41^{*}$ \\
\hline Número de vagem por planta & $0,44^{*}$ \\
\hline Número grãos por vagem & $0,90^{*}$ \\
\hline Massa de mil grãos & $n \tilde{o}$ \\
\hline
\end{tabular}

* significativo pelo teste T a 5\% significância; ns, não significativo

densidade de plantas sem a alteração do rendimento de grãos tem sido obtida pela pesquisa na faixa de densidade de 31 e 40 plantas $\mathrm{m}^{-2}$ (Linzmeyer Junior et al., 2008), 20 a 60 plantas $\mathrm{m}^{-2}$ (Peixoto et al., 2000) e 14 a 28 plantas $\mathrm{m}^{-2}(\mathrm{Oz}, 2008)$. Esse efeito deve-se ao fato de a competição inter e entre plantas estar em equilíbrio ou sob efeito compensatório entre os componentes da produção, que deverá ser ajustado para cada local e safra de cultivo. Nesse sentido, diferentes populações de plantas em soja interferem diretamente em aspectos morfofisiológicos da planta, resultando em menor ou maior competição intraespecífica; o conhecimento dessas interações faz-se importante, uma vez que possibilita manejar melhor o aproveitamento dos recursos disponiveis para o crescimento e rendimento de grãos da soja.

O cultivo de soja RR na região dos Campos de Cima da Serra, no Rio Grande do Sul, sob alta densidade de plantas promove redução no diâmetro da haste da soja, no número de ramificações por planta, no número de vagens por planta e no número de grãos por planta. Contudo, o rendimento de grãos, número de grãos por vagem e massa de mil grãos não sofrem influência da densidade de plantas, desde que as condições de fertilidade do solo e clima sejam favoráveis para a cultura da soja. A altura de planta aumentou com o incremento do número de plantas por área. O número de ramificações por planta e o número de vagem por planta são maiores no cultivar CD 213RR e independem da safra e da densidade de plantas, quando comparados aos do BRS 255RR. Sob condições de ocorrência de inverno antecipado, o cultivar BRS 255RR apresenta produtividade levemente superior à do CD 213RR.

\section{LITERATURA CITADA}

ARCE, G. D.; PEDERSEN, P.; HARTZLER, R. G. Soybean seeding rate effects on weed management. Weed Technol., v. 23 , n. 1, p. 17-22, 2009.

CASAGRANDE, E. C. et al. Expressão gênica diferencial durante déficit hídrico em soja. R. Bras. Fisiol. Veg., v. 13, n. 2, p. 168-184, 2001.

COMISSÃO DE QUÍMICA E FERTILIDADE DO SOLO CQFSRS/SC. Manual de adubação e de calagem para os Estados do Rio Grande do Sul e Santa Catarina. 10.ed. Porto Alegre: SBCS - Núcleo Regional Sul/UFRGS, 2004. $400 \mathrm{p}$

COMPANHIA NACIONAL DE ABASTECIMENTO CONAB. Lavouras. Disponível em: $<$ http:// www.conab.gov.br $>$ Acesso em: 09 out. 2008. On line. 2008

COODETEC. Guia de produtos 2009 Soja Sul. Cascavel: COODETEC, 2009. $55 \mathrm{p}$.

DUNCAN, W. G. Planting patterns and soybean yields. Crop Sci., v. 26, n. 1, p. 584-588, 1986.

EMPRESA BRASILEIRA DE PESQUISA AGROPECUÁRIA - EMBRAPA. Tecnologia de produção de soja - Região Central do Brasil 2005. Londrina: Embrapa Soja, 2004. 239 p.

EMPRESA BRASILEIRA DE PESQUISAAGROPECUÁRIA - EMBRAPA. Tecnologias de produção de soja - 2008 Londrina: Embrapa - Soja - Fundação Meridional, 2008a. 220 p. (Sistemas de produção/Embrapa Soja).

EMPRESA BRASILEIRA DE PESQUISA AGROPECUÁRIA - EMBRAPA. Tecnologias de produção de soja - Região Central do Brasil - 2009 e 2010. Londrina: Embrapa Soja; Embrapa Cerrados; Embrapa Agropecuária, 2008b. 262 p. (Sistemas de produção/Embrapa Soja, 13).

FAGERIA, C. K. et al. (Eds) Physiology of crop production. New York: Haworth Press, Incorporated, 2006 p. $117-130$

FEHR, W. R.; CAVINESS, C. E. Stages of soybean development. Ames: Iowa State University, 1977. 12 p.

HEIFFIG, L. S. et al. Fechamento e índice de área foliar da cultura da soja em diferentes arranjos espaciais. Bragantia, v. 65 , n. 2 , p. $285-295,2006$

Planta Daninha, Viçosa-MG, v. 28, n. 4, p. 887-896, 2010 
INMET. Boletim Agroclimatológico: Mapas do Boletim Agroclimatológico. Disponível em: $<$ http://

www.inmet.gov.br/climatologia/bol_agro/mapas.php $>$. Acesso em: 10 nov. 2009.

KARASU, A. et al. Genotype by environment interactions, stability, and heritability of seed yield and certain agronomical traits in soybean [Glycine max (L.) Merr.]. African

J. Biotechnol., v. 8, n. 4, p. 580-590, 2009.

KUSS, R. C. R. et al. Populações de plantas e estratégias de manejo de irrigação na cultura da soja. Ci. Rural, v. 38, n. 4, p. $1133-1137,2008$

LINZMEYER JUNIOR, R. et al. Influência de retardante vegetal e densidades de plantas sobre o crescimento, acamamento e produtividade da soja. Acta Sci. Agron., v. 30, n. 3, p. 373-379, 2008.

MALAVOLTA, E. Manual de nutrição mineral de plantas. São Paulo: Agronômica Ceres, 2006. 638 p.

MARCHIORI, L. F. S. et al. Desempenho vegetativo de cultivares de soja Glycine max (L.) Merrill em épocas normal e safrinha. Sci. Agric., v. 56, n. 1, p. 383-390, 1999.

MARTINS, M. C. et al. Época de semeadura, densidades de plantas e desempenho vegetativo de cultivares de soja. Sci. Agric., v. 56, n. 4, p. 851-858, 1999.
MOTTA, I. S. et al. Época de semeadura em cinco cultivares de soja. I. Efeito nas características agronômicas. Acta Sci. Agron., v. 24, n. 5, p. 1275-1280, 2002.

OZ, M. Nitrogen rate and plant population effects on yield and yield components in soybean. African J. Biotechnol., v. 7, n. 24, p. 4464-4470, 2008.

PEIXOTO, C. P. et al. Épocas de semeadura e densidade de plantas de soja: I. Componentes da produção e rendimento de grãos. Sci. Agric., v. 57, n. 1, p. 89-96, 2000.

PEIXOTO, C. P. et al. Características agronômicas e rendimento de soja em diferentes épocas de semeadura e densidades de plantas. Magistra, v. 13, n. 2, p. 77-86, 2001.

RAMBO, L. et al. Rendimento de grãos da soja em função do arranjo de plantas. Ci. Rural, v. 33, n. 3, p. 405-411, 2003.

SANTOS, J. B. et al. Avaliação de formulações de glyphosate sobre soja Roundup Ready. Planta Daninha, v. 25, n. 1, p. 165-171, 2007.

VASQUEZ, G. H.; CARVALHO, N. M.; BORBA, M. M. Z. Redução na população de plantas sobre a produtividade e qualidade fisiológica da semente de soja. R. Bras. Sementes, v. 30, n. 2 , p. $1-11,2008$. 